\title{
ESTIMULAÇÃO NEUROPSICOPEDAGÓGICA EM JOVEM COM DISTÚRBIO DO PROCESSAMENTO AUDITIVO CENTRAL: UM RELATO DE EXPERIÊNCIA
}

\author{
JONEILTON JOSÉ ARAUJO \\ PAULA NAYARA DOS SANTOS SILVA \\ CARLA DE CÁSSIA CARVALHO CASADO
}

\section{RESUMO}

O presente trabalho tem como objetivo apresentar relato de estimulação neuropsicopedagógica de um jovem com queixa de dificuldade de aprendizagem e diagnóstico de Distúrbio do Processamento Auditivo Central (DPAC). O caso relatado é o de um menino, 11 anos de idade, atendido em um hospital-escola de instituição pública da cidade de Belém do Pará. O relatório médico reportou alterações no desenvolvimento, especificamente atraso do desenvolvimento neuropsicomotor, desatenção e dificuldade de aprendizado, com diagnóstico DPAC. O relatório do neuropsicólogo descartou deficiência intelectual e apontou prejuízo quanto à atenção e memória auditiva; observou-se defasagem escolar e a necessidade de ser incluído em processo reabilitatório, devido à defasagem escolar evidenciada. $\mathrm{O}$ relato foi elaborado a partir da descrição do protocolo utilizada para possibilitar a estimulação e avaliação. Constou de 11 sessões. Duas de avaliação e nove de estimulação. O desempenho diário do paciente foi registrado qualitativa e quantitativamente em um roteiro de Controle de Desempenho, que consistia em divisão de tarefas pelas habilidades de linguagem, atenção e memória, bem como de habilidades sócio-afetivas, sensório-motor, orientação temporoespacial e pedagógicas (leitura e escrita). A partir disso, organizou-se um cronograma de estímulos com objetivo de auxiliar o paciente a criar e/ou desenvolver as habilidades cognitivas. Algumas atividades eram aplicadas nos dias da intervenção e outras foram preparadas para serem realizadas em casa, diariamente, com a presença dos responsáveis. O registro de desempenho indicou melhora significativa nas habilidades estimuladas, demonstrando efetividade no programa de estimulação neuropsicopedagógica desenvolvido e implementado no paciente.

Palavras-chave: Estimulação, Neropsicopedagógica, DPAC 


\section{SUMMARY}

The present study aims to present a report of neuropsychological pedagogical stimulation of a young man with complaint of learning disability and diagnosis of Central Auditory Processing Disorder (CAPD). The reported case is that of an 11-year-old boy attending a public institution hospital in the city of Belém do Pará. The medical report reported changes in development, specifically delayed neuropsychomotor development, inattention and learning difficulties, with a diagnosis of CAPD. The report of the neuropsychologist ruled out intellectual disability and pointed out impairment in attention and auditory memory; school deficits were observed and the need to be included in the rehabilitation process due to the evidenced school deficit. The report was elaborated from the description of the protocol used for stimulation and evaluation, that consisted of 11 sessions. Two evaluation and nine stimulation. The daily performance of the patient was recorded qualitatively and quantitatively in a Performance Control script, which consisted of division of tasks by language, attention, memory, social-affective, sensorimotor, temporo-spatial and pedagogical orientation (reading and writing). From this, a schedule of stimuli was organized to help the patient to create and / or develop cognitive abilities. Some activities were applied on the days of the intervention and others were prepared to be performed at home, daily, with the presence of those in charge. The performance record indicated a significant improvement in the stimulated abilities. Demonstrating effectiveness in the program of neuropsychological-pedagogical stimulation developed and implemented in the patient.

Key words: Stimulation, Neropsychopedagogic, CAPD

\section{1 - INTRODUÇÃO}

$\mathrm{Na}$ atualidade, emergem pesquisas que descrevem o distúrbio do processamento auditivo central e o relaciona com o baixo desempenho escolar. $\mathrm{O}$ interesse espelha o crescente número de crianças diagnosticadas com essa condição e o valor atribuído ao aprendizado para o pleno desenvolvimento do ser humano.

Processamento Auditivo Central (PAC) corresponde ao trajeto no qual o som percorre desde a passagem pela orelha externa, vias auditivas centrais, indo até o córtex cerebral. Ou, segundo a American Speech and Hearing Association - ASHA (2005), PAC é a eficácia e 
eficiência através da qual o sistema nervoso central (SNC) utiliza a informação auditiva, ou seja, refere-se ao processamento perceptual da informação auditiva no sistema nervoso central e às atividades neurobiológicas que o sustentam.

É através dessas habilidades auditivas que o sistema nervoso central discrimina diferentes sons, seleciona os sons ou a fala em ambiente ruidoso e para entender a fala, mesmo quando a qualidade sonora é ruim. Tal aspecto auxilia o ouvinte a permanecer escutando num certo período de tempo, podendo determinar se dois estímulos sonoros são iguais ou diferentes; identificar a direção e a distância da fonte sonora, bem como pode estabelecer a correspondência entre um som e suas fontes e seus significados. Também tem a função de fixar e recuperar estímulos sonoros e integrar essas informações auditivas com informações de diferentes modalidades sensoriais. As habilidades auditivas auxiliam na memória sequenciada e na organização de estímulos auditivos para o planejamento de respostas.

Para Pereira (2014) as habilidades auditivas necessárias para a compreensão da mensagem sonora, são: detecção, capacidade de identificar presença ou ausência de som; discriminação, capacidade que o indivíduo tem de perceber diferenças sutis mediante estímulos sonoros a que é exposto; localização, capacidade de identificar o sítio gerador do estímulo sonoro, mesmo variando a distância, direção e intensidade; figura-fundo: capacidade que o indivíduo tem de distinguir os sons da fala na presença de outros sons de fala semelhante; fechamento auditivo: capacidade de identificar os sons da fala quando apresentados de forma incompleta acusticamente; reconhecimento: capacidade de reconhecer sons previamente apresentados; compreensão: capacidade de interpretar o estímulo sonoro, ou seja, dar significado à informação auditiva captada; e memória: capacidade de armazenar e recuperar os estímulos sonoros.

O funcionamento correto de todas essas habilidades poderá determinar como o indivíduo receberá a informação sonora. Assim, o Distúrbio do Processamento Auditivo (DPAC), referese a dificuldades em uma ou mais dessas habilidades.

Numa condição de DPAC os impulsos elétricos que são codificados e enviados ao PAC não acontecem de forma normal, pois o processo de recebimento da informação sonora e a codificação do som não se processam da forma correta.

Para Pereira (2014), a primeira habilidade auditiva que se desenvolve é a de detecção auditiva, que surge ainda na vida intrauterina. Mais especificamente, segundo Northem e Downs (1989), no quinto mês de vida intrauterina o feto, com seu sistema auditivo periférico pronto, já ouve sons do corpo e a voz da mãe. 
Nesse sentido, o desenvolvimento das habilidades auditivas inicia na vida intrauterina e atinge a sua maturação por volta dos 12 aos 13 anos de idade. Para Pereira (2014), na medida em que há o amadurecimento dessas habilidades, o organismo se comporta de maneira cada vez mais eficiente diante dos estímulos acústicos. Dessa forma, as habilidades auditivas são desenvolvidas a partir de experiências no mundo sonoro e dependem da neuromaturação de estruturas complexas do sistema nervoso central.

Para Azevedo (2005), o PA, além das etapas de detecção, discriminação, e localização, também inclui a memória, reconhecimento e compreensão auditiva. Assim o Distúrbio do Processamento Auditivo Central (DPAC) surge quando a criança encontra dificuldade em lidar com as informações que chegam por meio da audição.

Conforme Bianchi (2011), a pessoa com DPAC tem audição normal, detecta os sons, mas não interpreta as informações, podendo, assim, apresentar dificuldades na compreensão e interpretação do que lhe é falado, o que pode interferir no processo de aprendizagem.

São diversas as possíveis causas para essa desordem em crianças e jovens. Entre estas Guedes (2015); Katz e Tillery (1997); Alvarez, Caetano e Nastas (1997) destacam: alterações funcionais, sem lesão específica ou diagnosticada, ou atraso de maturação das vias auditivas centrais. Tais disfunções ou atrasos de maturação têm como fatores de risco a prematuridade, intercorrências na gestação ou no parto, anóxia ou cianose, abuso de drogas e álcool na gestação, histórico familiar e também otites na infância.

De acordo com ASHA (2005), quase $20 \%$ da população, entre crianças, jovens e adultos, apresentam esse transtorno. Contudo para Chermak e Musiek (1997) apenas 2\% a 5\% da população de crianças em idade escolar são diagnosticadas e encaminhadas para tratamento, mesmo sendo um transtorno que impacta negativamente nos processos educacionais, de aprendizado e socialização.

O Distúrbio do Processamento Auditivo Central é devidamente conhecido pela medicina desde 1996 e afeta a capacidade da criança de compreender a fala e os processos de aprendizagem, tais como a alfabetização, a escrita, a interpretação de textos e compreensão dos enunciados dos problemas. Ou seja, ele afeta diretamente no rendimento escolar, sobretudo na alfabetização, consequentemente no desenvolvimento integral dos alunos.

Pereira (2014) relata diferentes formas de manifestações do DPAC em crianças, entre elas estão:

- No auditivo: o indivíduo parece não ouvir bem, mesmo tendo a audição dentro da normalidade; procura pistas visuais no rosto do falante; apresenta déficit em entender, seguir regras e ordens; demora em escutar e/ou entender quando chamado; apresenta dificuldades em 
localizar a fonte sonora; pede para repetir a conversa, durante o diálogo, ou utiliza muito as expressões: "hã?", “o quê?", "não entendi?”; tem dificuldade para entender conversas em ambientes ruidosos; apresenta dificuldades e/ou cansaço em manter a atenção auditiva; apresenta dificuldades em aprender músicas ou ritmos.

- No Comportamental: indivíduo que sofre do DPAC apresenta-se distraído, ansioso, impaciente, impulsivo, desorganizado e agitado ou apático com tendência ao isolamento; tem alterações em alguns sons da fala; apresenta dificuldades em se expressar no que se refere ao uso das estruturas gramaticais; tem dificuldades em lembrar palavras durante a conversa; tem dificuldade em compreender ideias abstratas ou entonações, piadas ou expressões com duplo sentido; manifesta déficit em contar história, manter uma sequência lógica, repassar recados; confunde-se ao contar fatos ou histórias.

Na aprendizagem: aluno que sofre de DPAC precisa copiar as tarefas dos outros em sala de aula, pois fica atrasado; apresenta dificuldades com regras de acentuação gráfica; demonstra baixo rendimento escolar na leitura, gramática, ortografia e na interpretação da leitura, influenciando assim, em várias matérias; apresenta troca de letras com sons parecidos, principalmente surdos e sonoros ( $/ \mathrm{b}, \mathrm{t} / \mathrm{d}, \mathrm{f} / \mathrm{v}, \mathrm{k} / \mathrm{g}, \mathrm{s} / \mathrm{z}, / \mathrm{g} / \mathrm{j} \mathrm{x} / \mathrm{ch}$ ); inverte as letras (b, p, d, q); na escrita; apresentar disgrafia e/ou deficiente caligrafia; possui dificuldade em elaborar um texto, resgatar ideias e organizá-las através da escrita; apresenta dificuldades em compreender o que lê; dificilmente consegue acompanhar o ritmo do ditado; apresenta déficit na interpretação dos problemas de matemática.

Para Pereira (2014), o DPAC pode ocorrer sozinho ou associado a outras patologias. Entre as mais comuns encontradas destacam-se o Desvio fonológico, Dificuldade de aprendizagem, Distúrbio/ Transtorno de Aprendizagem (Dislexia, Disortografia, Disgrafia, Discalculia), Transtorno do Déficit de Atenção e Hiperatividade (TDAH) e Distúrbio Específico de Linguagem (DEL). Como os sinais e sintomas não são exclusivos do DPAC, é importante realizar um diagnóstico diferencial por uma equipe multidisciplinar e mensurar a presença de comorbidades.

Assim, quando percebidas algumas dessas disfunções ou distúrbio auditivo, o primeiro passo é encaminhar o(a) paciente para o otorrinolaringologista, pois o transtorno de audição pode envolver dois aspectos: a perda auditiva, que é um impedimento da capacidade de detectar os estímulos sonora e o distúrbio de processamento auditivo, que é um impedimento da habilidade de analisar e/ou interpretar padrões sonoros.

Posteriormente o otorrino, deve encaminhar o paciente ao fonoaudiólogo. Segundo Pereira (2014), a avaliação específica do Processamento Auditivo Central é feita por esse 
profissional que tem conhecimento, treinamento e habilidade na aplicação dos testes, como também conhecimento na avaliação comportamental e na interpretação dos resultados obtidos. O objetivo do exame do PAC é avaliar a funcionalidade do sistema nervoso auditivo central, ou seja, as habilidades envolvidas na detecção, discriminação, reconhecimento, localização, compreensão, memória e atenção seletiva dos estímulos sonoros.

A avaliação do PAC permite estabelecer relações entre as habilidades auditivas, processos cognitivos e a memória. Desta forma, segundo Branco-Barreiro (2006), acrescenta-se ao protocolo de atendimento a avaliação de psicólogos, fonoaudiologia, pediatras e psicopedagogos para melhor diagnosticar e posteriormente melhor intervir.

Segundo Schirmer, Fontoura e Nunes (2004), a avaliação adequada dos déficits permite intervenções precoces que podem prevenir transtornos de aprendizagem e problemas de desenvolvimento. Os autores consideram ainda que todas as atividades de estimulação com crianças e jovens devem ser realizadas de forma lúdica, por meio de jogos e brincadeiras, para que a criança sinta prazer nas atividades propostas.

Também, é recomendável envolver a família e a escola. Neste sentido, Salles e Parente (2007) chamam a atenção para a importância de o professor conhecer as estratégias usadas pelo aluno no processo de leitura e escrita, para que ele possa adaptar as suas ações de acordo com essas estratégias de aprendizagem. Diante disso, as referidas autoras sugerem que é relevante, portanto, fornecer subsídios aos professores para que eles possam usar critérios claros e métodos condizentes aos objetivos da avaliação, pautados no conhecimento do desenvolvimento dos processos envolvidos na leitura e escrita.

Para o processo de reabilitação, a estimulação neuropsicopedagógica surgiu como um meio viável para potencializar o processo de aprendizagem e melhorar a qualidade de vida do paciente.

É importante ressaltar que, segundo a Sociedade Brasileira de Neuropsicopedagogia (2014), a neuropsicopedagogia é um campo da ciência que busca unir os campos da neurociência, psicologia e pedagogia para um novo formato de profissionais educadores, mais qualificados para lidar com as diversas especificidades que a escola atual apresenta.

Entre as atividades sugeridas destacam-se atividades de leitura que utilizem a memória visual como ponto de referência e atividades com música, para estimular a identificação e decodificação de sons.

Canto e Knabben (2002) citam exercícios corporais de movimentação no tempo e espaço para auxiliar na integração auditiva, técnicas que trabalham o hemisfério direito e esquerdo e a 
terapia ritmo-visual. Para a associação auditiva, sugerem trabalhar com estocagem de informação, atividades de leitura, trechos de textos.

Para desenvolver a organização de saída, são sugeridas as atividades que envolvam sequência e listagem que reforçam as habilidades do repertório do indivíduo; o caderno de anotações casa/escola ajuda a criança a organizar suas tarefas. A função não verbal pode ser desenvolvida com atividades que auxiliem na memória operativa por meios não verbais. Também, é importante trabalhar aspectos afetivo-emocionais por intermédio de vivências.

Portanto, para que o processo de aquisição da leitura e escrita ocorra de maneira eficaz, a criança precisa ser estimulada de maneira adequada para que as funções cognitivas sejam potencializadas. Considerando tal contexto, é importante ressaltar que, embora na literatura nacional existam estudos sobre programas de intervenção com escolares que apresentam distúrbios de aprendizagem, é importante que estas experiências sejam compartilhadas, tanto no intuito de disseminar possibilidades, uma vez que não há consenso de um método infalível, como também favorecer a possibilidade de levar em consideração as distintas realidades e necessidades individuais.

Desta forma tem-se, como objetivo, apresentar relato de estimulação neuropsicopedagógica de um jovem com queixa de dificuldade de aprendizagem e diagnostico de distúrbio do processamento auditivo central, descrevendo o processo de planejamento, as atividades propostas e os resultados obtidos.

\section{3 - MÉTODO}

\section{1 - Campo da experiência}

O jovem, submetido à estimulação neuropsicopedagógica relatada no presente estudo foi atendido numa unidade de atenção à saúde da criança e do adolescente, no âmbito de um hospital-escola de uma instituição pública de ensino superior, localizada na cidade de Belém do Pará. A Unidade recebe crianças e adolescentes encaminhados pelos profissionais de saúde que compõem o quadro do hospital, incluindo o de Otorrinolaringologia. Possui um protocolo de avaliação, por meio do qual todos os indivíduos encaminhados são avaliados e encaminhados para iniciar estimulação e receber orientação psicopedagógica. O jovem foi atendido individualmente. 
O responsável pelo participante foi consultado e assinou um Termo de Consentimento Livre e Esclarecido, conforme a resolução 196/96 da Comissão Nacional de Ética em Pesquisa -CONEP - (Brasil, 1996).

\section{2 - Participante}

O estudo contou com a participação de um jovem, de 11 anos de idade, em fase de aquisição da leitura e escrita, com diagnóstico de Distúrbio do Processamento Auditivo, frequentando o terceiro ano do ensino fundamental, repetindo pela terceira vez a referida série.

O jovem apresenta atraso na aquisição e/ou desenvolvimento da leitura e escrita. Os critérios de inclusão no projeto basearam-se em dificuldades para acompanhar a classe, por mais de 5 meses consecutivos, repetência por inaptidão, diagnóstico e avaliação inicial feita pelo otorrinolaringologista e pela fonoaudióloga, avaliação do neuropsicólogo, descartando a hipótese de deficiência intelectual e confirmando desempenho aquém do esperado para sua faixa etária.

\section{3 - Instrumentos}

Nas duas primeiras sessões com o jovem foram feitos o rastreio sobre as habilidades por meio de entrevista com o cuidador e exercícios de compreensão da linguagem, execução de comandos simples, teste diagnóstico com tabela alfabética e de família silábica, atividades metalinguísticas de consciência fonológica, identificação de palavras em material literário (livros, revistas e outros) e leitura, interpretação de textos.

Da $3^{\text {a }}$ a $11^{\text {a }}$. sessão, em conformidade ao protocolo da unidade, os materiais utilizados foram livros de histórias, caderno de desenho, caderno de caligrafia, lápis de cor, operações matemáticas com figuras geométricas, de animais, de objetos, massinha de modelar e atividade de alfabetização diversa. Além destes merece destaque os jogos e materiais pedagógicos: 


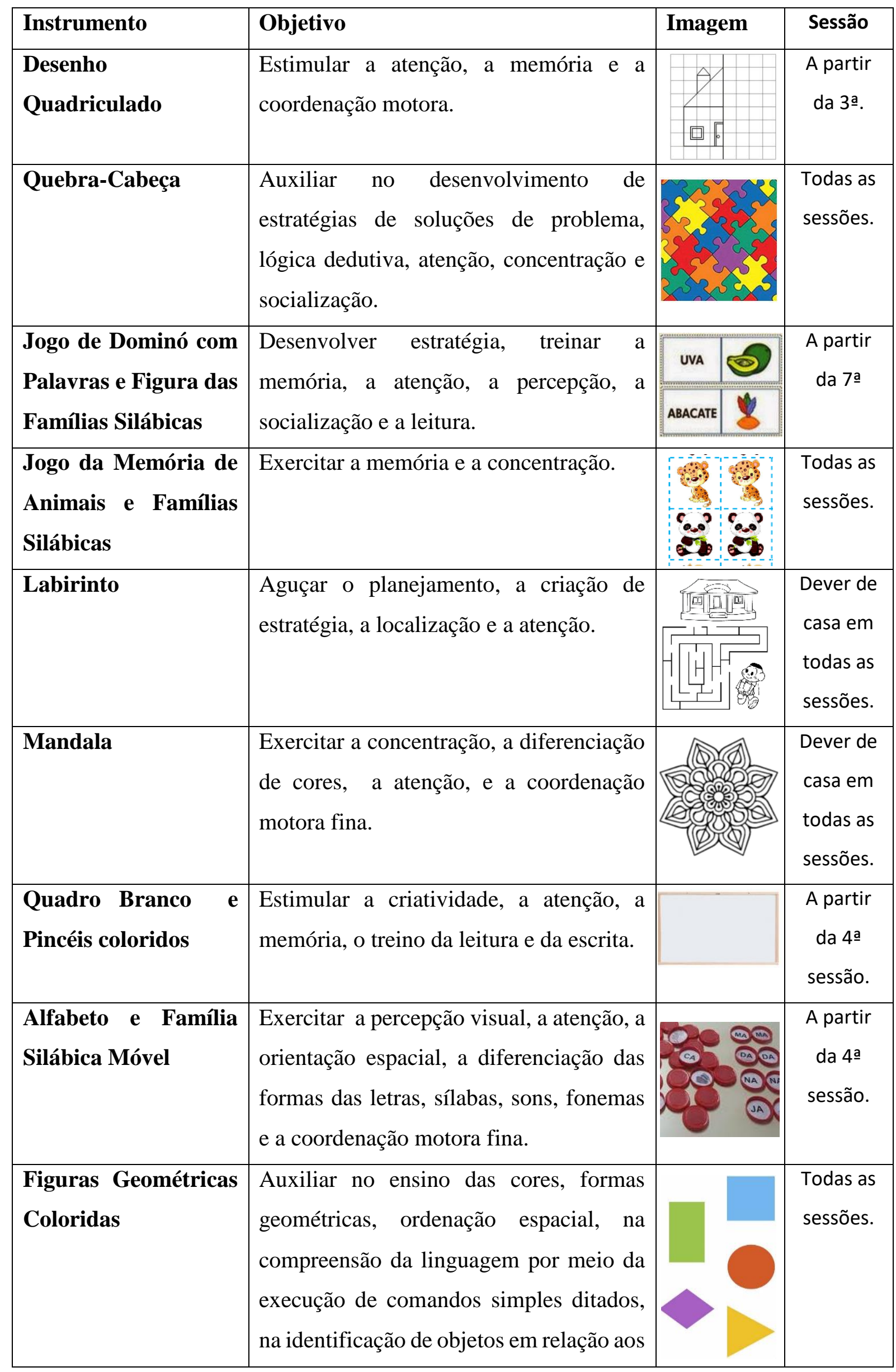




\begin{tabular}{|c|c|c|c|}
\hline & $\begin{array}{l}\text { outros e ao espaço, desenvolvimento da } \\
\text { percepção, concentração e atenção. }\end{array}$ & & \\
\hline Dado Silábico & $\begin{array}{l}\text { Exercitar leitura, escrita, formação de } \\
\text { palavras, treino da memória e da } \\
\text { linguagem pela repetição das sílabas, } \\
\text { palavras e de seus sons. }\end{array}$ & $\underbrace{\bar{\omega}}_{\square}$ & $\begin{array}{l}\text { A partir } \\
\text { da 4a } \\
\text { Sessão. }\end{array}$ \\
\hline Flor Silábica & $\begin{array}{l}\text { Trabalhar leitura, escrita, construção de } \\
\text { palavras, treino da memória e da } \\
\text { linguagem pela repetição das sílabas, } \\
\text { palavras e de seus sons. }\end{array}$ & త & $\begin{array}{l}\text { A partir } \\
\text { da 6a } \\
\text { Sessão. }\end{array}$ \\
\hline $\begin{array}{l}\text { História com } \\
\text { Sequência Lógica }\end{array}$ & $\begin{array}{l}\text { Estimular a coordenação motora, a } \\
\text { atenção, a imaginação, a criação, a } \\
\text { organização, a ordenação, a } \\
\text { concentração, a percepção e o raciocínio } \\
\text { lógico }\end{array}$ & & $\begin{array}{l}\text { Todas as } \\
\text { sessões. }\end{array}$ \\
\hline Jogo dos 7 Erros & $\begin{array}{l}\text { Trabalhar a identificação e localização de } \\
\text { objetos, o planejamento de ações e } \\
\text { movimento, o pensamento abstrato, a } \\
\text { memória de curto prazo e a atenção. }\end{array}$ & & $\begin{array}{l}\text { Dever de } \\
\text { casa em } \\
\text { todas as } \\
\text { sessões. }\end{array}$ \\
\hline Jogo de Xadrez & $\begin{array}{l}\text { Estimular as funções de raciocínio } \\
\text { matemático, memória, atenção, } \\
\text { planejamento, impulsividade, resolução } \\
\text { de problemas e socialização. }\end{array}$ & & $\begin{array}{l}\text { Usado a } \\
\text { partir da } \\
\text { 2a sessão. }\end{array}$ \\
\hline Jogo Lince & $\begin{array}{l}\text { Desenvolver e ampliar a percepção viso- } \\
\text { espacial, nomeação de figuras, aprimorar } \\
\text { a rapidez de reação, ativar a memória } \\
\text { operacional e auxiliar na socialização e } \\
\text { linguagem. }\end{array}$ & 2 & $\begin{array}{l}\text { Usado a } \\
\text { partir da } \\
\text { 2a sessão. }\end{array}$ \\
\hline Desenho Simétrico & $\begin{array}{l}\text { Estimular a criatividade, a percepção } \\
\text { viso-espacial, a capacidade de } \\
\text { representação e atenção. }\end{array}$ & & $\begin{array}{l}\text { Dever de } \\
\text { casa em } \\
\text { todas as } \\
\text { sessões. }\end{array}$ \\
\hline
\end{tabular}




\begin{tabular}{|c|c|c|c|}
\hline $\begin{array}{l}\text { Quadro de Pregas e } \\
\text { fichas silábicas para } \\
\text { Alfabetização }\end{array}$ & $\begin{array}{l}\text { Atrair a atenção do aluno despertando o } \\
\text { interesse do mesmo para a atividade. É } \\
\text { utilizado como suporte de informações, } \\
\text { apresentando-as de maneira progressiva e } \\
\text { dinâmica. Auxiliar na fixação do } \\
\text { conteúdo. Nele o conteúdo é maleável e a } \\
\text { criança pode brincar de criar palavras e } \\
\text { pseudopalavras. }\end{array}$ & $\begin{array}{l}\text { SIAPO } \\
\text { a pit to } \\
\text { vela } \\
\text { a e ilolut }\end{array}$ & $\begin{array}{l}\text { A partir } \\
\text { da 5a. }\end{array}$ \\
\hline $\begin{array}{l}\text { Desenho } r \text { com } \\
\text { Sequência } \\
\text { ou Alfabética }\end{array}$ & $\begin{array}{l}\text { Desenvolver a coordenação motora fina, } \\
\text { a atenção, ordenação, fixação da } \\
\text { sequência numérica e alfabética. }\end{array}$ & 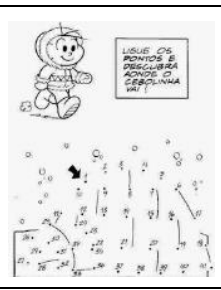 & $\begin{array}{l}\text { Dever de } \\
\text { casa em } \\
\text { todas as } \\
\text { sessões. }\end{array}$ \\
\hline Origami & $\begin{array}{l}\text { Estimular as zonas do tato, motora e } \\
\text { visual, auxiliar no desenvolvimento da } \\
\text { inteligência espacial, atenção, } \\
\text { imaginação, criatividade, memória e } \\
\text { autoestima. }\end{array}$ & & $\begin{array}{l}\text { A partir } \\
\text { da 7ạ. }\end{array}$ \\
\hline
\end{tabular}

Os materiais e instrumentos escolhidos tiveram por critério de seleção aqueles que: estimulam a memória operacional; a atenção e concentração para realizar tarefas; os que auxiliam relacionar as unidades sonoras simples e representá-las graficamente, tendo como base as letras do nome do paciente; auxiliem-no a escrever letras, silabas e frases, bem como o ajude a escrever as palavras separadamente em frases; que estimule a linguagem através de situações diversas; desenvolva o raciocínio lógico matemático e resolva situações-problema; trabalhe conceitos de números e quantidades, estabelecendo ordenação, comparações, semelhanças e diferenças, fazendo seriação e classificação; auxilie a desenvolver a lateralidade e a coordenação motora fina.

\section{4 - Procedimentos}

O processo de estimulação neuropsicopedagógica ocorreu ao longo de 11 sessões, cada qual com duração de 120 minutos. O desempenho diário do paciente foi registrado qualitativa e quantitativamente em um roteiro de Controle de Desempenho, que consistia em divisão de 
tarefas pelas habilidades de linguagem, atenção, memória sócio-afetiva, sensório-motor, orientação tempo-espaço e pedagógicas (leitura e escrita).

$\mathrm{Na}$ primeira sessão, os responsáveis foram informados sobre os procedimentos de estimulação e sobre as normas da unidade. Nessa sessão, foi ouvida a queixa principal dos responsáveis com relação ao jovem. Após, os responsáveis foram liberados e foi desenvolvida atividade de rastreio sobre as habilidades de linguagem oral e escrita.

Na segunda sessão foram avaliadas as habilidades de atenção, memória sócio-afetiva, sensório-motora, orientação temporo-espacial e pedagógica. Para tanto foram usados exercícios de compreensão da linguagem, por meio da execução de comandos simples dados pelo examinador, teste diagnóstico com tabela alfabética e de família silábica, para avaliar as noções de linguagem oral/escrita, com o intuito de saber se a criança consegue reconhecer letras e formar palavras por meio da leitura e escrita; atividades metalinguísticas de consciência fonológica, para saber se o paciente reconhecia os sons das letras, a dimensão sonora das palavras e a identificação de palavras em material literário (livros, revistas e outros); leitura, interpretação de textos.

As atividades foram transcritas em uma tabela na qual se registravam as habilidades dentro das áreas a serem estimuladas. Cada área foi dividida em dois desempenhos: um referente a agosto, início das intervenções; dois referentes a dezembro, fim das intervenções. Em cada desempenho registraram-se três categorias: $0=$ não realiza, $1=$ realiza com ajuda e 2 $=$ realiza de forma independente.

A partir desses resultados organizaram-se as sessões de estimulação com objetivo de auxiliar o paciente a criar e/ou desenvolver as habilidades cognitivas. Algumas atividades eram aplicadas nos dias da intervenção e outras foram preparadas para serem realizadas em casa, diariamente, com a presença dos responsáveis.

Nas sessões 3 a 11 ocorreram as estimulações com os materiais neuropsicopedagógicos de que mais adiante falaremos.

A sala onde ocorreram os atendimentos era pequena, com mesa quadrada, que proporcionou uma maior aproximação com o jovem e facilitou a comunicação. Os materiais para realização das atividades foram disponibilizados conforme o planejamento de cada sessão.

Ao término das sessões de estimulação, o desempenho do jovem foi analisado e as informações compiladas em um relatório cujas informações foram compartilhadas e esclarecidas com o responsável pela criança. 


\section{5- RESULTADOS}

A análise da produção do jovem antes e após a intervenção podem ser assim descritos.

\section{1 - Linguagem}

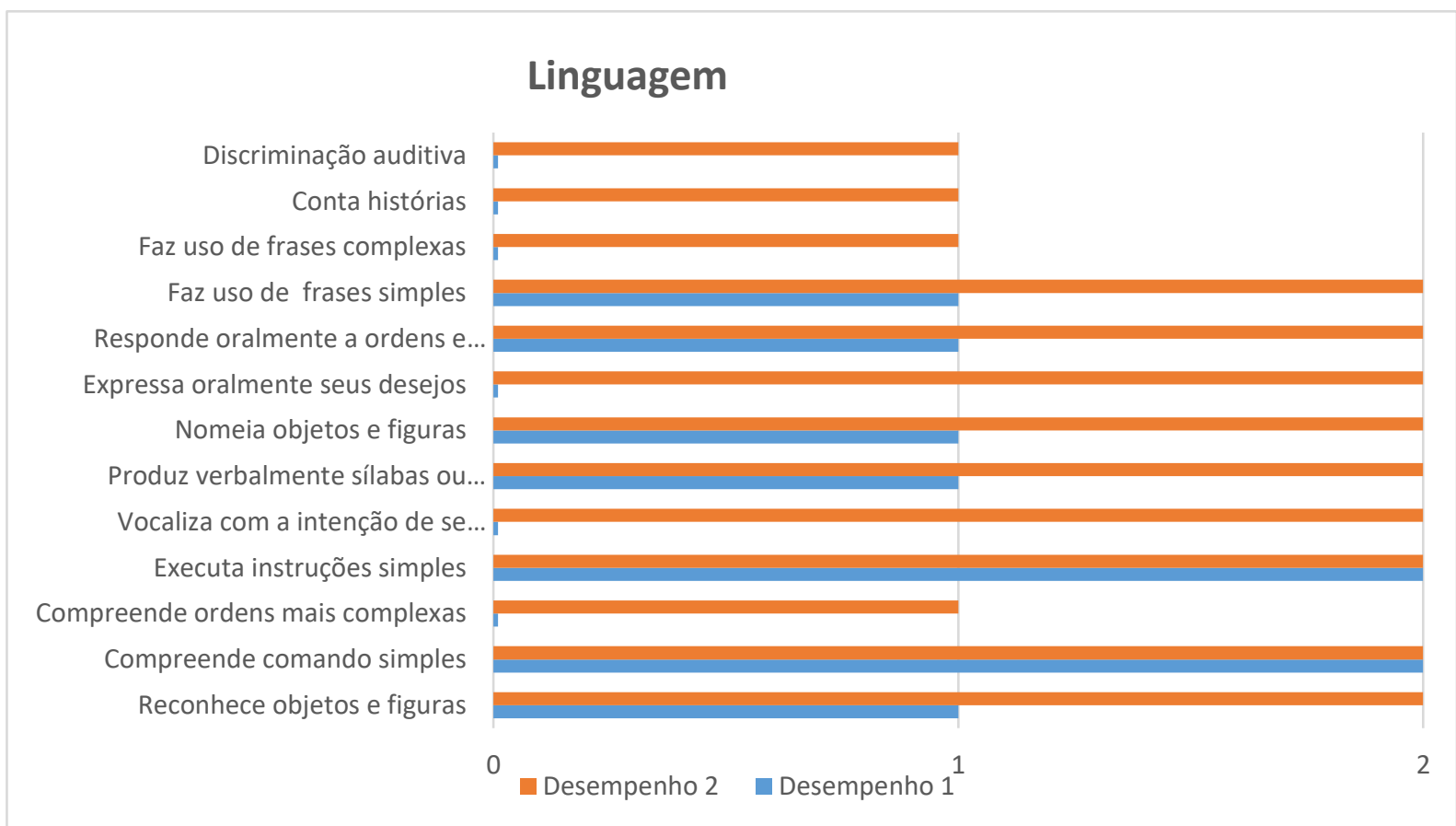

Gráfico 1 - Resultados do antes e depois da intervenção na área da linguagem.

Como se observa no desempenho 1 do gráfico 1, na linguagem, o jovem apresentava compreensão oral abaixo do esperado para sua faixa etária, com prejuízo nas habilidades de expressão oral. Isso se manifestava pelo uso restrito do vocabulário, com resposta simplificada de uma única palavra e frases curtas ou comunicadas por sinais (apontando). Pouco interagia com o interlocutor. Quando solicitado a alguma tarefa, perguntas ou leituras de frase, o mesmo sempre requeria repetições; nas atividades de nomeação demonstrava significativa dificuldade quanto à nomeação de figuras e quando não reconhecia a imagem raramente se beneficiava de 
pista semântica e fonética. Apresentava dificuldades na pronúncia de certos fonemas, principalmente no início da palavra e, eventualmente, omitia e fazia substituição de sons, algo comum em portadores de DPAC.

Além disso, o paciente demonstrava acentuada dificuldade na discriminação auditiva; na contação de histórias; no uso de frases complexas; na expressão oral de seus desejos; na vocalização com a intenção de se comunicar; na compreensão de ordens complexas. Nos outros itens avaliados como reconhecer objetos e figuras; compreender comandos simples; executar instruções simples; produzir verbalmente sílabas ou palavras; nomear objetos e figuras; responder oralmente a ordens e perguntas; e fazer uso de frases simples, evidenciavam-se significativas dificuldades. Entretanto, conseguia executar as atividades com ajuda.

O objetivo das intervenções foi estimular a linguagem através de diversas situações. Como estratégia de intervenção, optou-se por usar linguagem simples e familiar acessível à compreensão; conto e reconto de histórias, descrição de gravuras; estimular diversas formas de comunicação.

Os instrumentos utilizados foram: história com sequência lógica, flor e dado silábico, figuras geométricas coloridas, alfabeto e família silábica móvel, quadro didático branco, Token Test, quadro de pregas, fichas silábicas para alfabetização, atividades pedagógicas diversas e contação de história.

Assim, obtivemos os resultados apresentados no desempenho 2 do gráfico 1, os quais evidenciam progressivo desenvolvimento na área da linguagem, principalmente nos aspectos do reconhecimento de figura, no compreender e executar comandos complexos, verbalização de sílabas (vogais e família do B e L), palavras, nomeação de objetos, figura e expressão oral de seus desejos com uso de frases simples. Sendo perceptível maior evolução no vocalizar com intenção de comunicar e na expressão de seus desejos por frases mais elaboradas (Ex: "na próxima vez quero jogar xadrez").

\subsection{Atenção}




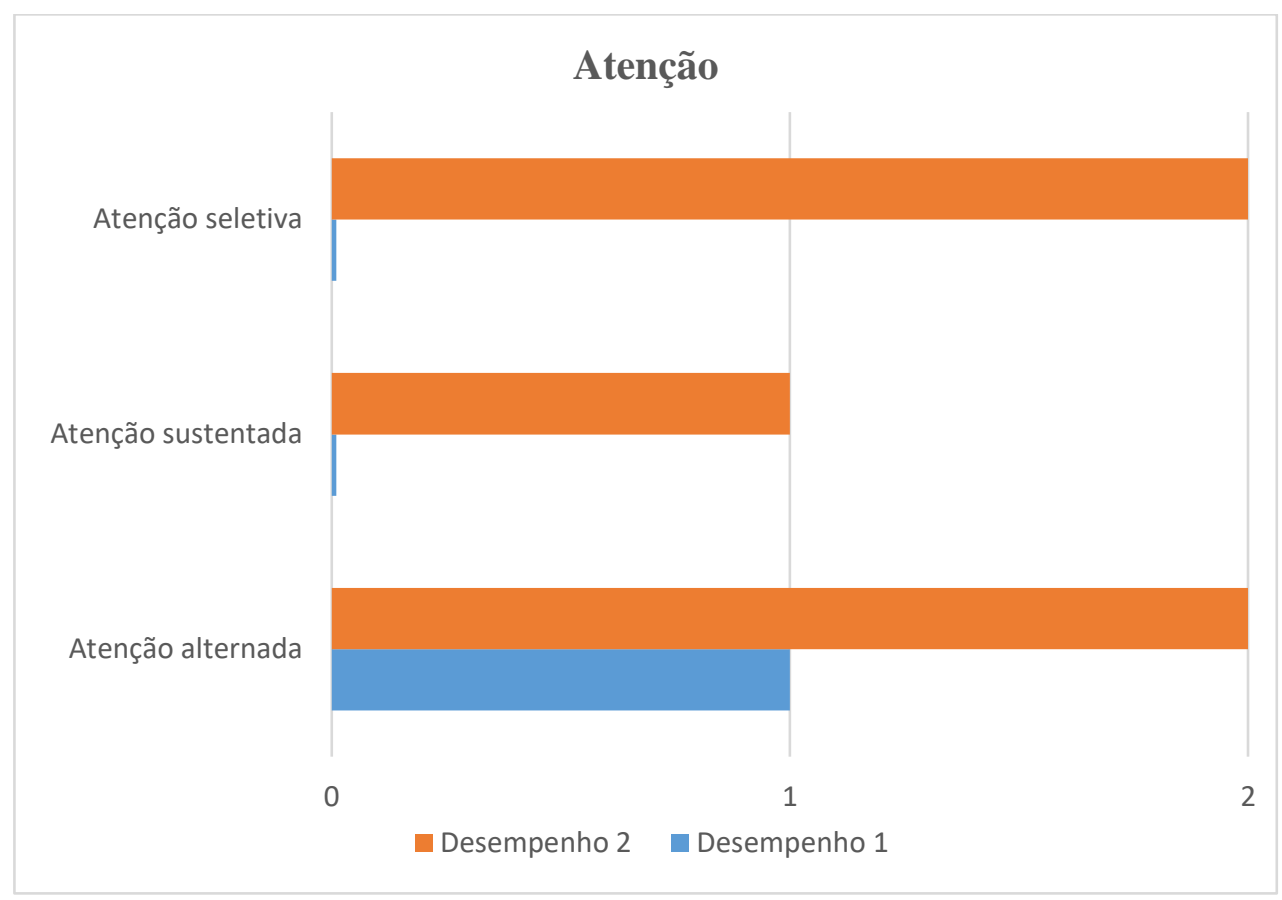

Gráfico 2 - Resultados do antes e depois da intervenção na área da Atenção.

Como se observa no desempenho 1 do gráfico 2, no campo da atenção, o jovem apresentou desempenho inferior em tarefas que avaliam: atenção alternada, que é a capacidade de se alternar o foco atencional entre um estímulo e outro na execução de uma tarefa; atenção sustentada, que é a habilidade de manter-se focado durante uma atividade contínua e repetitiva, por um longo período de tempo e sem distrações; atenção seletiva, que é uma capacidade de estar atento a uma atividade, selecionar as informações importantes, excluindo os estímulos ao redor, e/ou ignorar informações irrelevantes. Demonstrava dificuldade em se concentrar, perdendo o foco com facilidade e demostrava-se desinteressado, apático e desmotivado.

O objetivo das intervenções foi estimular a atenção e concentração para realizar tarefas. Para tanto optou-se pelas estratégias de dar instruções claras, precisas e pouco numerosas; centrar as atividades o mais lúdico e concreto possível e, sempre que possível, serem manuseados pelo paciente.

Os materiais utilizados foram: jogo da memória, jogo dos 7 erros, jogo de xadrez, jogo nince, quebra-cabeça, jogo de dominó, origami, desenho com sequência numérica ou alfabética, desenho simétrico, história com sequência lógica, alfabeto e família silábica móvel, quadro didático branco, mandala, labirinto, desenho quadriculado, quadro de pregas e fichas silábicas para alfabetização.

Assim, como observado no desempenho 2 do gráfico 2 os resultados demonstram considerável desenvolvimento na área da atenção, principalmente na atenção sustentada e seletiva, áreas fundamentais para a alfabetização. 


\section{3 - Memória}

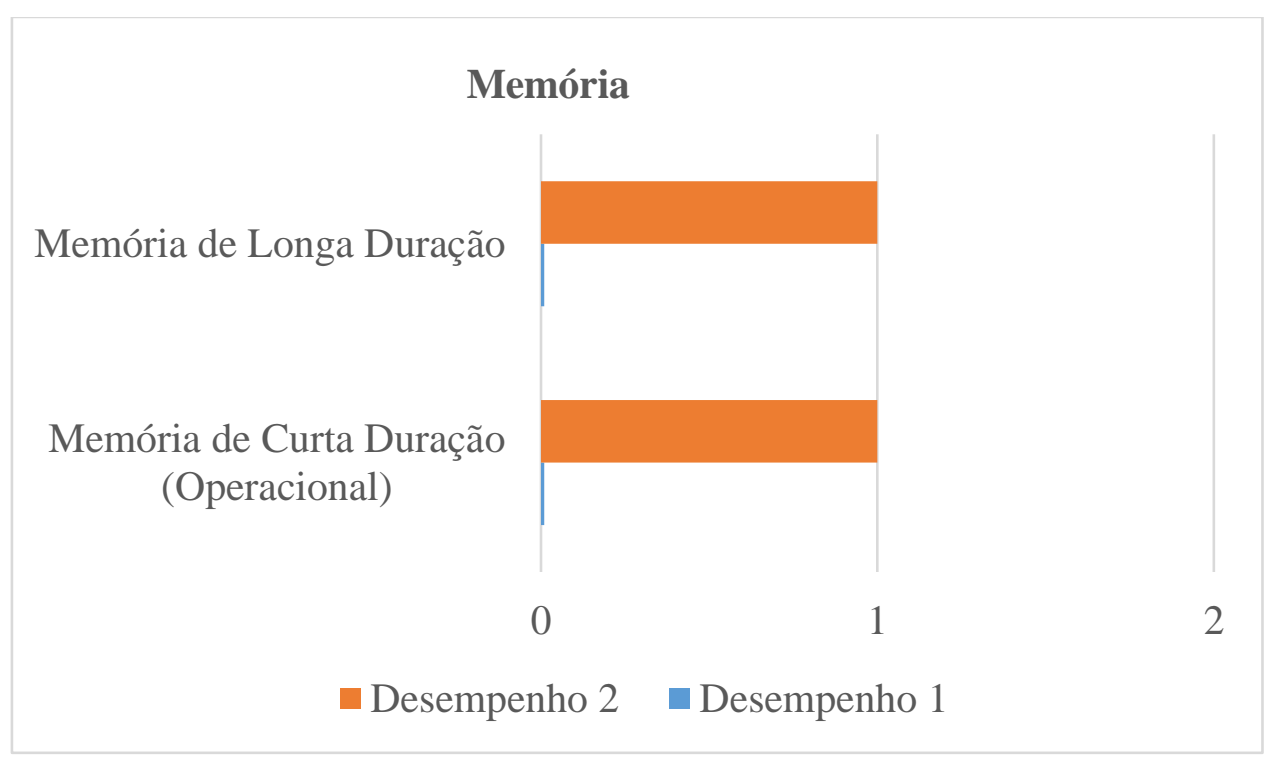

Gráfico 3 - Resultados do antes e depois da intervenção na área da memória.

Como se observa no desempenho 1 do gráfico 3, no campo da memória verificou-se desempenho deficitário tanto na memória de curta duração (operacional), que é a capacidade de manter a informação recente, quanto na memória de longa duração (prazo), que armazena dados de dias atrás, até décadas. Ou seja, o paciente apresentava dificuldades acentuadas tanto na capacidade de reter, quanto na capacidade de recuperar informações em curto período de tempo.

O objetivo das intervenções foi estimular a memória operacional. Para isso optou-se pela estratégia de organizar informações por categorias, usar música, apresentar as informações de várias maneiras, usar estratégias múltiplas de aprendizagem para apresentar a mesma informação, repetir o conteúdo em várias sessões, inclusive com atividades para serem efetuadas diariamente em casa, realizar associação e confecções com o cotidiano, utilizar fotos e imagens.

Os materiais utilizados foram: livros de histórias, caderno de desenho, caderno de caligrafia, lápis de cor, operações matemáticas com figuras geométricas, de animais, de objetos, atividade de alfabetização diversa, origami, desenho com sequência numérica ou alfabética, quadro de pregas, fichas silábicas para alfabetização, jogo lince, jogo de xadrez, jogo dos 7 erros, história com sequência lógica, flor e dado silábico, figuras geométricas coloridas, alfabeto e família silábica móvel, quadro didático branco, jogo da memória com animais e com as 
famílias, jogo de dominó com palavras e figura das famílias silábicas, quebra-cabeça e desenho quadriculado.

Assim, como observado no desempenho 2 do gráfico 3 obtivemos importante ganho na área da memória operacional e de longo prazo. O paciente já consegue manter-se consciente quanto a uma informação recebida e, com ela, desenvolver uma atividade, algo fundamental para a aprendizagem.

\section{4 - Habilidades Sócio-afetivo, Sensório-motor e Orientação Temporo-espacial}

\section{Habilidades Sócio-afetivo, Sensório-motor e Orientação Temporo- espacial}

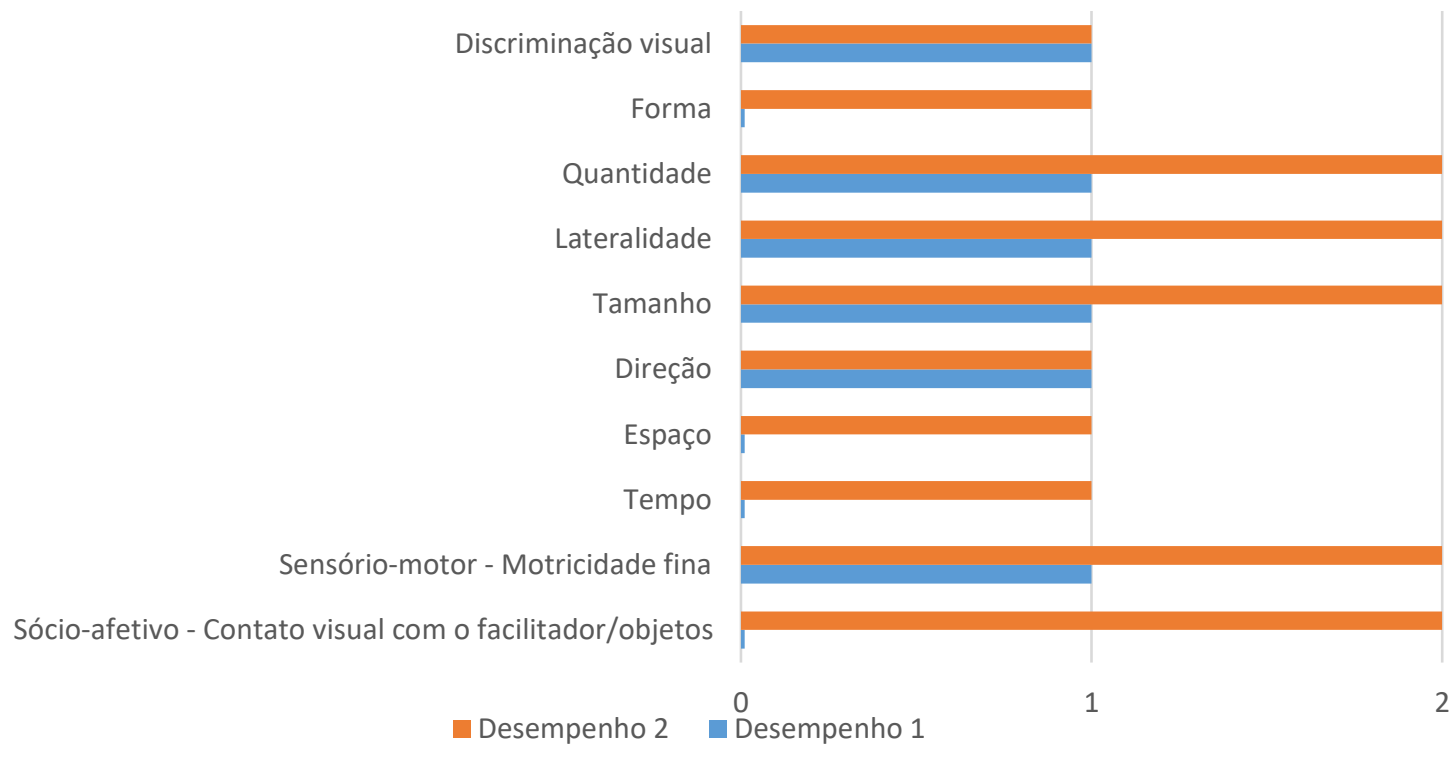

Gráfico 4 - Resultados do antes e depois da intervenção na área das habilidades sócio-afetivo, sensóriomotor e orientação temporo-espacial.

Como se observa no desempenho 1 do gráfico 4, no campo das habilidades sócio-afetivo, sensório-motor e orientação temporo-espacial, o jovem apresentou desempenho inferior quanto à percepção tempo-espaço-forma, além de apresentar pouco contato visual. Também percebeuse performance abaixo da média nos quesitos de motricidade fina, direção, tamanho, lateralidade, quantidade e discriminação visual. Isso se evidenciava de forma mais clara na dificuldade em executar o raciocínio lógico para solucionar problemas e construir novas estratégias. 
O objetivo era desenvolver a lateralidade, a postura; a coordenação motora fina, o contato visual com objeto e com o facilitador, a noção de tempo, espaço, tamanho, quantidade, forma, e percepção das cores, posições, orientações e diferenças e semelhanças entre palavras, letras, imagens, objetos. Para isso optou-se por trabalhar com atividade pedagógicas diversas, desenho livre, pintar desenhos e atividade de psicomotricidade.

Os materiais utilizados foram: caderno de desenho, caderno de caligrafia, lápis de cor, origami, desenho simétrico, jogo lince, jogo de xadrez, flor e dado silábico, figuras geométricas coloridas, alfabeto e família silábica móvel, quadro didático branco, mandala, labirinto, jogo da memória, jogo de dominó, quebra-cabeça, desenho quadriculado, massinha de modelar, desenho com sequência numérica ou alfabética e atividade de alfabetização diversa.

Assim, os resultados observados no desempenho 2 do gráfico 4 demonstram expressivo ganho nas áreas de percepção tempo-espaço-tamanho-lateralidade-quantidade, bem como acentuada evolução no contato visual com o facilitador e na motricidade fina. O paciente já consegue distinguir entre os dias da semana, sabe dizer onde está, identifica letras semelhantes, separa sílabas e consegue copiar frases.

\subsection{Habilidades Pedagógicas}




\section{Pedagógico}

22- Escrita do primeiro e segundo sobrenome 21- Escrita do primeiro e segundo nome

20- Escrita família do L

19- Escrita família do $B$ 18- Escrita palavras com vogais

17- Escrita vogais 16- Interpretação de imagens

15- Alfabetização - leitura família do L em sequência

14- Alfabetização - leitura família do L aleatória 13- Alfabetização - leitura de palavras da família do B e.

12- Alfabetização - leitura família do B aleatória

11- Alfabetização - leitura família do B em sequência 10- Alfabetização - leitura de palavras com Vogais 9- Alfabetização - leitura vogais intermitente

8- Alfabetização - leitura vogais em sequência

7- Alfabeto - letras/fonemas

6- Cálculo - subtração

5- Cálculo - adição

4- Nomeiar numerais

3- Conceitos matemáticos

2- Reconhecimento de formas

1- Nomeação de formas

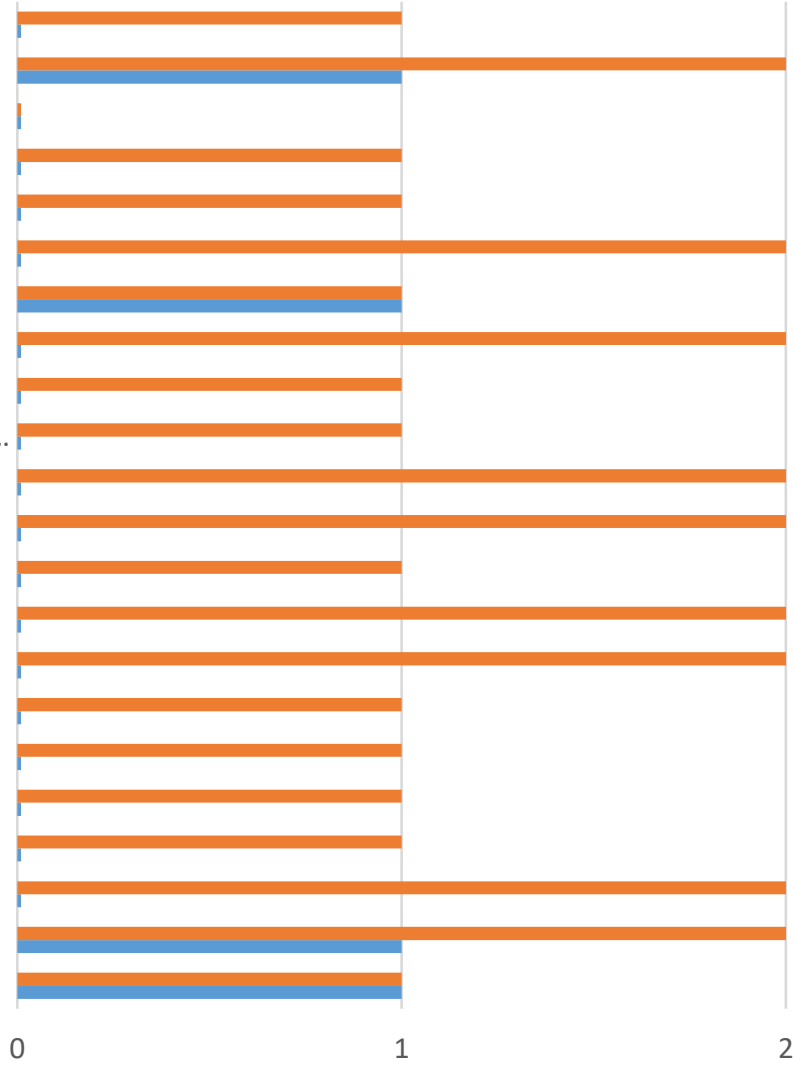

nesempenho 2 Desempenho 1

Gráfico 5 - Resultados do antes e depois da intervenção na área das habilidades pedagógicas leitura e escrita.

O gráfico 5 talvez seja o que melhor expressa o avanço do paciente a partir das estimulações feitas, comprovando a evolução do paciente em direção à alfabetização. $\mathrm{O}$ desempenho 1 demonstra importante atraso quanto às habilidades acadêmicas do paciente. Ele não apresentava os repertórios de conceitos matemáticos, nomear numerais, cálculo - adição, cálculo - subtração, alfabeto - letras/fonemas, alfabetização - leitura de vogais em sequência, alfabetização - leitura de vogais intermitentes, alfabetização - leitura de palavras com vogais, alfabetização - leitura família do b em sequência, alfabetização - leitura família do b aleatória, alfabetização - leitura de palavras da família do b e vogais, alfabetização - leitura família do 1 aleatória, alfabetização - leitura família do L em sequência, escrita das vogais, escrita de palavras com vogais, escrita família do b, escrita família do l, escrita do primeiro e segundo sobrenome.

Com ajuda o paciente conseguia nomear e reconhecer formas, interpretar imagens, escrever o primeiro e segundo nome somente e, quase inelegível. Apresentava dificuldade para identificar palavras iguais ao modelo. Não fazia a conversão grafema-fonema para ler palavras, 
ainda que sílabas simples. O mesmo contava com dificuldade de 0 a 10, mas sem ordenação ou sequenciação.

O objetivo era estimular a relação entre unidades sonoras simples, sua representação gráfica, tendo como base as sílabas do nome do paciente; escrever letras, silabas e frases concretas; aprender a escrever as palavras separadamente em frases; desenvolver o raciocínio lógico matemático; resolver situações-problema; trabalhar conceitos de números e quantidades estabelecendo comparações, semelhanças e diferenças, fazendo seriação e classificação.

Cabe aqui ressaltar que nas primeiras sessões, sempre quando se iniciava o trabalho pedagógico para alfabetização, o paciente demostrava-se desinteressado, apático e desmotivado. Isso acontecia quando lhe era apresentado material para treino de leitura e escrita. Esse comportamento se mantinha mesmo quando o paciente conseguia ler algumas sílabas e efetuava a leitura de palavras simples.

Quando se percebeu a desmotivação do paciente, mesmo quando o reforço de aprender era adquirido, optou-se por trabalhar algumas sessões de forma mais lúdica para desenvolver o vínculo terapêutico. Essa estratégia resultou em bons progressos, principalmente quanto ao responder verbalmente aos comandos, utilizando frases completas.

Para desenvolver habilidades pedagógicas optou-se pelas estratégias de linguagem escrita, utilizando alfabeto móvel; estimular a formação de sílabas simples partindo das letras do nome do paciente; propor atividades de escrita para se manter a escrita em linha reta; escrever letras, silabas, frases e pequenos textos; realizar contagens de acordo com as quantidades solicitadas; perceber a relação dos números, medindo objetos, observando calendário, idade do aluno e dos familiares, relógio, etc.

Os materiais utilizados foram: quadro de pregas e fichas silábicas para alfabetização, desenho simétrico, flor e dado silábico, alfabeto e família silábica móvel, quadro didático branco, jogo da memória, famílias silábicas, livros de histórias, caderno de desenho, caderno de caligrafia, lápis de cor, operações matemáticas com figuras geométricas, de animais, de objetos, massinha de modelar, atividade de alfabetização diversas e jogo de dominó com palavras e figura das famílias silábicas.

Assim, como demonstra o desempenho 2 do gráfico 5, os resultados são significativos. O paciente passou a reconhecer boa parte das letras do alfabeto, números das unidades simples, algumas famílias silábicas e consegue ler e escrever algumas palavras com ajuda. Um dos ganhos mais importantes foi a aquisição da escrita do próprio nome de forma independente, pois, a partir disso, o paciente conseguiu tirar sua carteira de identidade, assinando-a sozinho. 


\section{6 - CONSIDERAÇÕES FINAIS}

A implementação do programa de intervenção neuropsicológica mostrou-se possível de ser realizada com aderência da criança à sua execução. Nesse sentido foi possível observar, no caso estudado, moderada e progressiva melhora nas habilidades de linguagem, atenção e memória. Isso demonstra a efetividade do programa de intervenção neuropsicopedagógica desenvolvido e implementado no paciente com Distúrbio do Processamento Auditivo Central.

Assim, como limitações do estudo, destaco a impossibilidade de controlar o impacto da escola nos ganhos, pois precisaria de grupo controle para isso. Entretanto isso podem ser superadas em estudos futuros. Pois, aumentando a amostra, e com grupo controle isso nos permitirá análises estatísticas mais robustas para apontar a eficácia do método aqui desenvolvido. Outra possibilidade é a de promover um programa com maior número de sessões e com maior periodicidade semanal. Entretanto, apesar das limitações apontadas, foi possível observar significativas melhoras nos indicadores cognitivos do paciente.

\section{REFERÊNCIAS}

ASHA, American Speech-Language-Hearing Association. Distúrbios auditivo (central) de processamento (Relatório Técnico), 2005.

ALVAREZ, A. M. M. A.; CAETANO, A. L.; NASTAS, S. S. Processamento auditivo central: avaliação e diagnóstico. São Paulo: Fono atual, 1997

AZEVEDO, M.F. Avaliação audiológica no primeiro ano de vida. In: LOPES FILHO O. Tratado de Fonoaudiologia. $2^{\mathrm{a}}$ ed. São Paulo: Tecmedd; 2005.

BIANCHI, Lana. Distúrbio do processamento auditivo central, a doença da incompreensão. Correio Brasiliense. Brasília, 15 mai. 2011.

BRANCO-BARREIRO, Fátima Cristina Alves. Contribuição da Fonoaudióloga Fátima Cristina Alves Branco-Barreiro, Doutora em Psicologia (Neurociências e Comportamento) e Professora Adjunta em Audiologia da Uniban, São Paulo, 2006. Disponível em: <www.fonoesaude.org/pa.htm>. Acesso em: dezembro de 2018.

CANTO, Cleunisse R. de L.; KNABBEN, Mylene Saturnino de B. Introdução ao processamento auditivo. Virtus, Tubarão, v. 2, n. 1, p. 323-334, 2002.

GUEDES, Mariana Cardoso. Causas e tratamentos da desordem de processamento auditivo. Blog Deficiência Auditiva 20 de janeiro de 2015. Entrevista concedida a Juliana Tavares. Disponível em: < http://deficienciaauditiva.com.br/causas-e-tratamentos-dadesordem-de-processamento-auditivo/ > . Acesso em: dezembro de 2018. 
KATZ, J.; TILLERY, K.L. Uma introdução ao processamento auditivo. In Lichtig, I; CARVALHO, R. M. M. Audição: abordagens atuais. Carapicuíba. Pró fono, 1997.

Northern JL, Downs MP. Audição em crianças. 3a ed. São Paulo: Manole; 1989.

PEREIRA, Kátia Helena. Manual de orientação: transtorno do processamento auditivo TPA. Florianópolis: DIOESC, 2014

SALLES, J. F.; PARENTE, M. A. M. P. Funções neuropsicológicas em crianças com dificuldades de leitura e escrita. Psicologia: Teoria e Pesquisa, Brasília, v. 22, n.2, p. 153-162, 2006.

SCHIRMER, C. R.; FONTOURA, D. R.; NUNES, M. L. Distúrbios da aquisição da linguagem e da aprendizagem. Jornal de Pediatria, Porto Alegre, v. 80, n. 2, supl., p. 95-103, 2004.

SOCIEDADE BRASILEIRA DE NEUROPSICOPEDAGOGIA. História da Neuropsicopedagogia no Brasil. Disponível em: < http://www.sbnpp.com.br/historia-daneuropsicopedagogia-no-brasil/> . Acesso em dezembro de 2018. 